\title{
Reducing provider-held stigma and improving young client satisfaction in Bangladesh: Findings from a Link Up evaluation
}

Population Council

Follow this and additional works at: https://knowledgecommons.popcouncil.org/departments_sbsr-hiv

Part of the Demography, Population, and Ecology Commons, Family, Life Course, and Society

Commons, Gender and Sexuality Commons, International Public Health Commons, and the Maternal and Child Health Commons

How does access to this work benefit you? Let us know!

\section{Recommended Citation}

Population Council. 2016. "Reducing provider-held stigma and improving young client satisfaction in Bangladesh: Findings from a Link Up evaluation," Link Up Study Brief. Washington, DC: Population Council. 
In Bangladesh, HIV prevalence has been estimated to be less than one percent in the general population, however, sex workers, men who have sex with men (MSM), and transgender people are disproportionately affected. ${ }^{1,2}$ Research in Bangladesh has documented high levels of discrimination by health service providers toward people living with $\mathrm{HIV}^{3,4}$ and avoidance of health services by people living with HIV due to fear of potential discrimination from providers. ${ }^{5}$ Stigma can inhibit uptake of critical HIV and sexual and reproductive health and rights (SRHR) services, particularly among young people. ${ }^{6}$ Stigma has been associated with lower rates of HIV-related knowledge, testing, disclosure, social support, physical health, mental health, and adherence to antiretroviral treatment. ${ }^{7-9}$ Furthermore, research in Bangladesh has documented stigma (unrelated to HIV) among healthcare providers toward sex workers ${ }^{10}, \mathrm{MSM}^{11}$, and transgender people (called "hijra" in Bangladesh) ${ }^{12}$, which inhibits disclosure of important health-related information to providers.

To address stigma in Bangladesh, a training program was designed and evaluated among service providers as part of Link Up, a global project led by the International HIV/AIDS Alliance designed to improve the SRHR of young people. The Link Up project in Bangladesh consisted of facility- and community-based integrated HIV and SRH activities targeting young people (ages 15 to 24) at higher risk of stigmatization due to HIV, premarital sex, or being a sex worker, MSM, hijra, or "pavement-dwelling" person (someone who is typically migrant and lives on streets or in an improvised dwelling). Health care providers from local Link Up partner Marie Stopes International Bangladesh (MSIB) participated in various training activities throughout the life of the project. These trainings aimed at sensitizing health care providers to the needs and rights of young people at high risk of stigmatization-such as sex workers, sexual minorities, or young people who engage in premarital sex. The Population Council collaborated with MSIB to evaluate whether stigma reduction

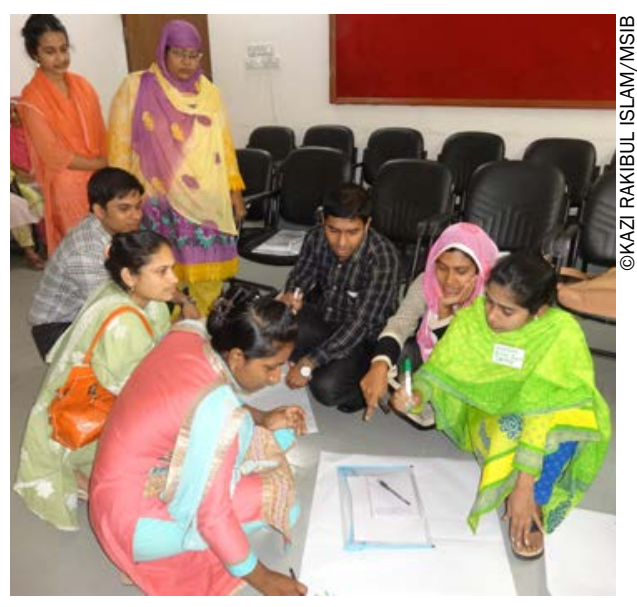

As part of Link Up, the Population Council evaluated a training program designed to reduce provider stigma toward young, marginalized clients.

\section{KEY MESSAGES}

Stigma reduction trainings had a positive impact on providers' beliefs, attitudes, and the quality of care provided to young people living with or at risk of HIV.

Client satisfaction with the quality of services increased after training.

Participatory, small-group trainings with collective reflection can be an effective approach to stigma reduction among providers. 
trainings improved provider attitudes toward these young marginalized populations, and whether the trainings improved young clients' perceptions of MSIB services.

\section{METHODS}

\section{Intervention: a stigma reduction training package}

Integration training: Over 1,000 healthcare providers (doctors, paramedics/nurses/family welfare visitors, and counselors) at 270 health facilities in 38 target districts in Bangladesh were trained by local partners on meeting the HIV and SRHR needs of young, vulnerable clients. This initial two-day "integration training" was based on a global Link Up integration training guide developed by the International HIV/AIDS Alliance. ${ }^{13}$ The training addressed providers' potential concerns about the risk of HIV transmission from clients, related stigma toward people living with HIV due to fear of transmission, and measures to minimize transmission risk. The Link Up integration training typically also included a one-day session on HIV stigma, sexuality, gender, and key populations.

Supplemental stigma training: To address concerns among Link Up project members that the initial

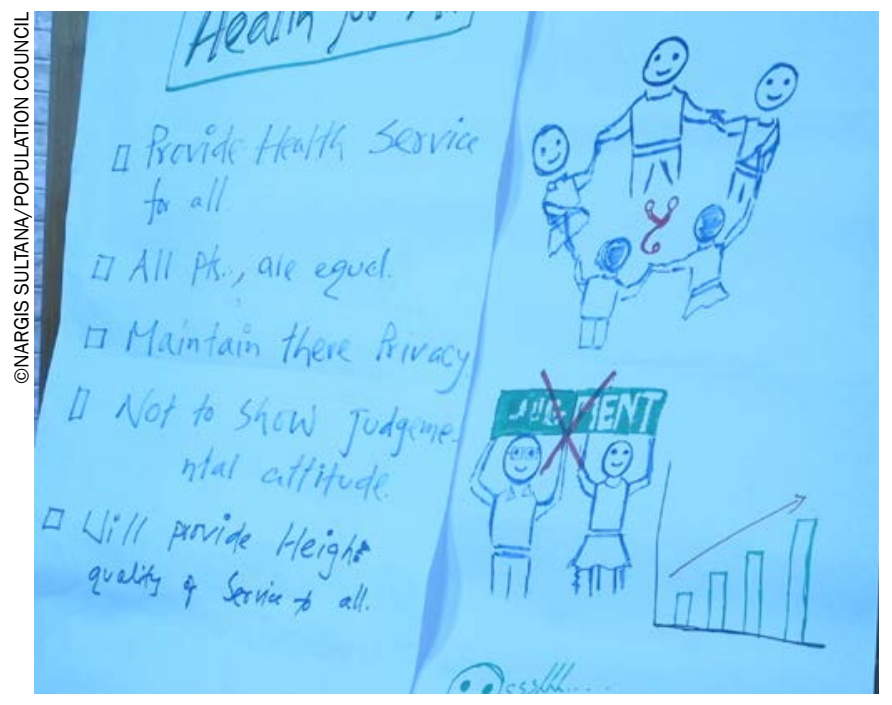

Health care providers participated in interactive trainings at which they reflected on their values and attitudes related to HIV and youth sexuality. training might not have been sufficient to have a significant impact on providers' attitudes, a oneday supplemental training focused on stigma reduction was added. This supplemental training highlighted messages on social stigma and encouraged reflection on personal values around key populations and youth sexuality. After a fourday "training of trainers," in which two experts led a group of MSIB trainers through stigma reduction activities, the MSIB trainers conducted one-day supplemental stigma trainings for their provider colleagues. Box 1 gives an overview of the stigma training curriculum, adapted from a toolkit used in other settings. ${ }^{14}$

\section{Evaluation: study design, data collection methods, and population}

At baseline, before the initial integration training, 300 providers were recruited and given a selfadministered questionnaire measuring stigmatizing attitudes toward young populations. All service providers receiving the initial integration training during a six month period were invited to participate in the study. The questionnaire, which was adapted from a validated, field tested tool previously used in multiple settings in Asia, Africa, and the Caribbean ${ }^{15,16}$, contained a series of questions to assess training, experience with people living with $\mathrm{HIV}$, and workplace and personal drivers of stigma and discrimination. The questionnaire was given to the same 300 providers again at midterm, six months after the initial integration training and before participating in the one-day supplemental stigma training, and finally at endline, five to six months after the supplemental stigma training. A subset of 25 doctors, nurses/paramedics, and counselors also participated in in-depth interviews after completing the endline survey. To assess the impact of provider training on client satisfaction, cross-sectional surveys of MSIB clients aged 15-24 were implemented before and after the supplemental stigma training. The study was approved by the Population Council Institutional Review Board (New York, USA) and Bangladesh Medical Research Council Ethical Review Committee (Dhaka, Bangladesh). 


\section{BOX 1 SUPPLEMENTAL STIGMA TRAINING: OVERVIEW OF ACTIVITIES, TECHNIQUES, AND INTENDED OUTCOMES}

Naming stigma through pictures involves viewing pictures illustrating stigma; analyzing forms, causes, and effects of stigma; and starting to share personal stories of what they have witnessed.

In Our own experiences of stigma, participants share a time in their lives when they felt stigmatized, first with a partner and then with the larger group. This exercise helps participants understand personal feelings and long-term effects of stigma.

Participants create a key population Stigma problem tree to recognize the causes and resulting effects of stigma. Forms of stigma faced by key populations at risk of HIV are written on cards posted on a wall; causes represent the tree's "roots," actual forms of stigma form the "trunk," and effects

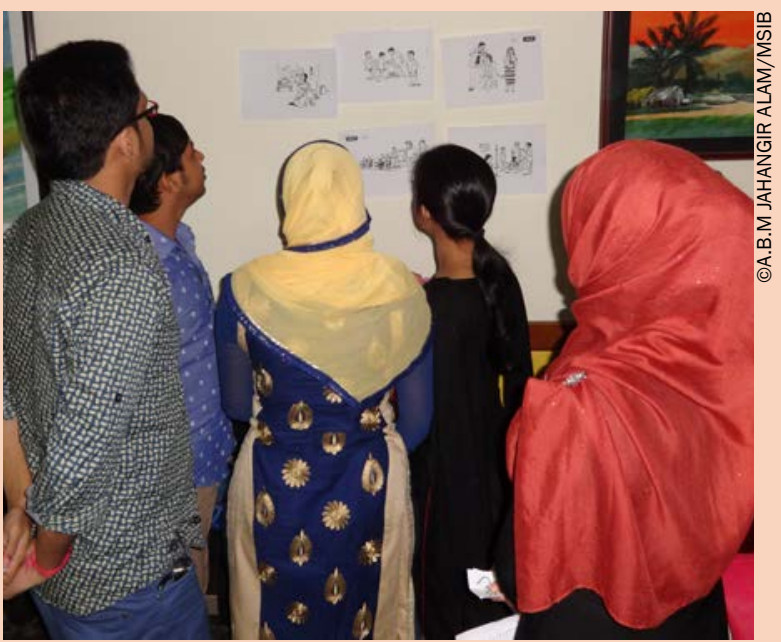

One of the supplemental stigma training activites included viewing pictures illustrating stigma to raise awareness of the different forms of stigma. of stigma are the "leaves" and "branches."

In Values clarification, participants fill out individual questionnaires about their values. Reflection and discussion about how values affect judgments of others leads participants to recognize how attitudes and beliefs influence stigmatizing behavior.

In Talking about sex, participants work in separate gender groups to discuss their questions about sex that are then shared and discussed; leads participants to understand barriers to talking openly about sex and how this can lead to stigma.

Things people say is a group brainstorming session of what people say about different key populations at risk of HIV. The session helps participants understand how language can stigmatize subgroups, and how words may have a harmful impact.

In Understanding gender and sexuality terminologies participants match gender- or sexuality-related terminology cards with their corresponding definitions to develop a clearer understanding of gender and sexual minority definitions and constructs, and agreement on acceptable terminologies to be used by service providers.

MSM and transgender case studies consist of small group discussions about different case studies based on health service experiences of MSM and transgendered persons. The session leads to enhanced ability to identify stigma-related barriers for MSM and transgendered persons to access and receive appropriate health services.

Be the change is a paired role-playing exercise to practice challenging stigma in the workplace and elsewhere. It is designed to increase providers' ability to personally challenge or change stigmatizing attitudes among peers and in other situations.

Writing a charter for a stigma-free service consists of small group work discussing ideas to promote stigma-free health services. Ideas are promoted in a larger group, and ways forward are discussed. This session enables understanding of how to develop ideas for promoting stigma-free services when providers return to their workplace. 


\section{RESULTS}

\section{Service provider characteristics}

Most service providers were female (91 percent), married (75 percent), and Muslim (79 percent).

Providers were a median age of 31 years old (interquartile range 26-38); 59 percent had been a provider for six or more years and 93 percent spent most of their time working in a clinic run by a non-governmental organization (e.g., MSIB). More than half (52 percent) of the providers were nurses, paramedics or family welfare visitors; 32 percent were counselors; and 16 percent were doctors.

\section{Shift in provider attitudes about people who live with HIV}

In some cases, providers' attitudes improved significantly after the integration training and remained stable after the supplemental stigma training. For example, the percentage of providers who reported that people living with HIV should feel ashamed dropped significantly from 35 percent at baseline to 20 percent after the initial integration training, yet after the supplemental stigma training the change was less pronounced

They presented stigma by showing different pictures. For example,

an HIV-positive patient went to the

hospital and shared his problems.

The service providers kept

unusual distance wearing gloves

unnecessarily while checking up.

AIDS is not transmitted through

touch; thus treating patients wearing

two gloves is stigma. Whenever we

take blood, we need to wear [gloves],

but using the stuff unnecessarily,

getting scared to see them, keeping

distance, is stigma.

-Female doctor, 39 years old (from 20 percent to 16 percent). Similarly, after the integration training, the percentage of providers who agreed with the statement that people living with HIV have had many sexual partners dropped considerably from baseline (57 percent) to midterm (46 percent), with a less dramatic reduction after the supplemental stigma training (46 percent to 43 percent). And, after the initial integration training, the percentage of providers who said people living with HIV should be allowed to have babies if they choose rose to 53 percent from 40 percent at baseline, but only increased slightly (to 56 percent) after the supplemental stigma training.

Il if a young unmarried pregnant

woman comes to me, I do make

judgment towards her. But the

training led me to understand that

such judgmental attitudes need to be

avoided.

—Female nurse/paramedic, 32 years old

\section{Supplemental training reduces stigma against key populations among providers}

The supplemental stigma training seemed to have had an additional substantial impact on providers' attitudes toward marginalized populations, as illustrated in Figure 1. Significantly fewer providers reported being unwilling to provide services, fearing disease transmission, or judging clients to be immoral if they were a young sexually active person, including MSM or sex workers. In-depth interviews indicated that the training had helped providers become more self-aware, which they considered to be the first step in overcoming judgmental attitudes, feelings and beliefs. Many providers said the training helped them shift their mindset to "treating the disease" instead of focusing on clients' "disgraceful" behaviors (premarital sex, homosexual relations, sex work) that are considered contrary to Bangladesh's conservative values and religious beliefs. Although the word "rights" was not explicitly mentioned, most providers said the training had 


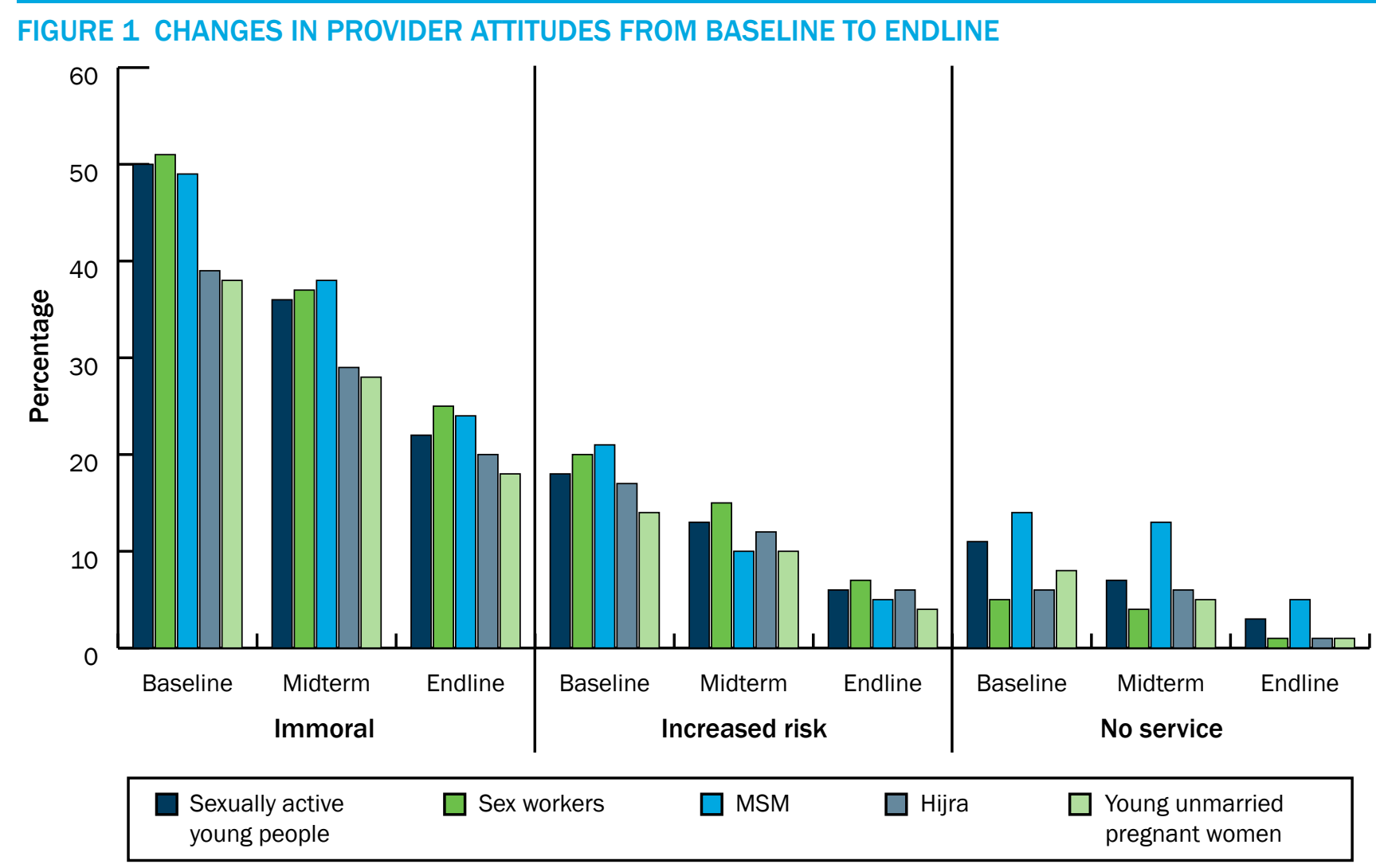

No service $=$ Providers agree they prefer not to provide services Increased risk = Providers agree clients "put me at higher risk" of acquiring disease Immoral = Providers agree clients engage in immoral behavior

reinforced their duty to treat all clients equally as human beings entitled to services, regardless of background, circumstances, beliefs, or behaviors, and that the training had led them to provide better care.

\section{Before I joined [the] Link Up project}

I used to think...how am I going to

deal with transgender people and

the MSM. I was kind of afraid, but

when I attended counselor training,

I realized that they are part of us. I

should provide service to them as

they are part of our society.

-Male counselor, 44 years old

\section{Client characteristics}

The client exit survey was completed by 264 clients in the first round and 367 in the second round. The majority of participants in both rounds were aged 20 to 24, with limited education (44-49 percent had no/incomplete primary education). The only significant difference between the two cohorts of clients was a significant increase in the percentage of women between the first and second rounds (40 percent to 55 percent). Sex workers, MSM, garment workers, and pavement dwellers were represented in both rounds. However, only 13 hijra participated in the first round and five in the second round.

\section{Clients' perceptions of service delivery improvements}

Overall, clients were more likely to report discussing with service providers that they were a member of a stigmatized population after the supplemental training; this was particularly noticeable among 
MSM (68 percent to 87 percent). Although enacted stigma (feeling that the provider acted in a negative or discriminatory way) was reported by only 4 percent of clients after the first training, no clients reported experiencing enacted stigma after the second training. The most substantial decrease was reported by sex workers (10 percent to 0 percent). Client satisfaction increased significantly after the supplemental stigma training, as shown in Figure 2.

\section{CONCLUSIONS}

The Link Up training package had a positive impact on providers' beliefs and attitudes, and on the quality of care provided to young people living withor at increased risk of contracting-HIV, including young key populations. Fear- and values-based stigma were significantly reduced after both training interventions-some more so after the second training. The value of the supplemental stigma training appears to be supported by increases in client satisfaction with services.

Although the study had several limitations, including the lack of a comparison group in the provider cohort study and no baseline measurement among clients before the first integration training, substantial improvements in provider services and attitudes were recorded among several survey items. These improvements were further substantiated by young clients who expressed greater satisfaction with provider interactions and services. Furthermore, by the end of the study period, providers had had greater exposure to these young, marginalized communities. This exposure alone may have made providers more accepting over time. Given the high level of success and acceptability of the training methods used in this study, MSIB has already institutionalized and scaled up the participatory training approach used in the second stigma training for all of their service providers in Bangladesh.

Reaching young people at risk of being denied the health services they need and deserve due to provider stigma is essential. The participatory stigma training methods utilized here-naming stigma through pictures, small group work exploring feelings of stigma, brainstorming about how language affects stigma-can be valuable tools to help providers reflect on their own values, attitudes, and practices; these methods can enable them

\section{FIGURE 2 CLIENT SATISFACTION WITH SERVICE DELIVERY BEFORE AND AFTER SUPPLEMENTAL STIGMA TRAINING}
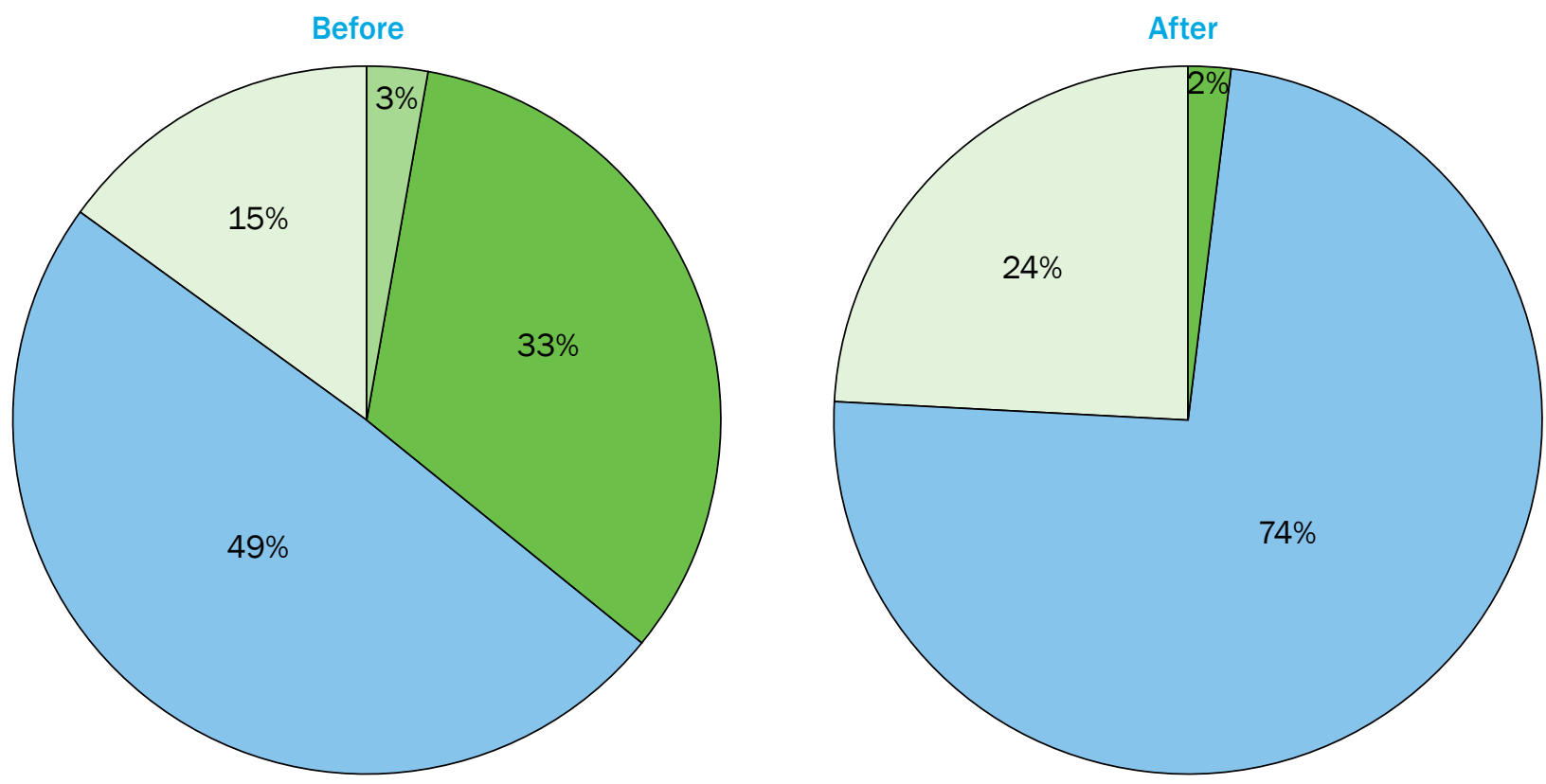

Not satisfied

$\square$ Neutral

Satisfied

Very satisfied 
to "be the change." We recommend funding of similar interventions more broadly to tackle the major barrier of stigma experienced in health care settings.

\section{REFERENCES}

1. Global AIDS Response Progress Report; Annual Progress Report, Bangladesh 2015. Available at: http://www.unaids.org/sites/default/ files/country/documents/BGD_narrative_ report_2015.pdf

2. National AIDS/STD Programme. 2011. National HIV serological surveillance, 2011 Bangladesh. Dhaka: National AIDS/STD Programme.

3. James P. Grant School of Public Health. 2009. Draft report. "People living with HIV stigma index" study in Bangladesh. BRAC University: Dhaka. Accessed at http://www. stigmaindex.org/sites/default/files/reports/ Bangladesh percent20People percent20Living percent20with percent20HIV percent20Stigma percent20Index percent20Report percent202009.pdf.

4. Ahsan, Ullah AK. 2011. "HIV/AIDS-related stigma and discrimination: a study of health care providers in Bangladesh," J Int Assoc Physicians AIDS Care 10:97-104.

5. Hasan, MT et al. 2012. "Internalized HIV/ AIDS-related stigma in a sample of HIV-positive people in Bangladesh," J Health Popul Nutr 30:22-30.

6. Delany-Moretlwe, S et al. 2015. "Providing comprehensive health services for young key populations: needs, barriers and gaps," J Int AIDS Soc. 26;18(2 Suppl 1):19833.

7. Katz, IT et al. 2013. "Impact of HIV-related stigma on treatment adherence: systematic review and meta-synthesis," J Int AIDS Soc 16(3 Suppl 2):18640.

8. Smith, R, K Rossetto, and BL Peterson. 2008. "A meta-analysis of disclosure of one's HIV-positive status, stigma and social support," AIDS Care 20:1266-75.
9. Pulerwitz, J et al. 2010. “Reducing HIV-related stigma: lessons learned from Horizons research and programs," Public Health Rep 125:272-81.

10. Katz, KR et al. 2016. “'I won't be able to go home being pregnant': sex work and pregnancy in Dhaka, Bangladesh," Cult Health Sex 2:1-14. [Epub ahead of print]

11. Chan, PA and OA Khan. 2007. "Risk factors for HIV infection in males who have sex with males (MSM) in Bangladesh," BMC Public Health 7:153.

12. Khosla, N. 2009. "HIV/AIDS interventions in Bangladesh: what can application of a social exclusion framework tell us?," J Health Popul Nutr 27:587-97.

13. Stackpool-Moore L, Singh A. 2015. Sexual and reproductive health and rights, and HIV 101 workshop guide: A guide to facilitating a workshop on linking up HIV and sexual and reproductive health and rights with young key populations. Brighton, UK: International HIV/ AIDS Alliance.

14. Kidd, R, S Clay, and C Ciiya. 2007. Understanding and challenging HIV stigma: toolkit for action. Brighton, UK: International HIV/AIDS Alliance, CHANGE Project, Academy for Education Development (AED), International Research on Women (ICRW), PACT Tanzania.

15. Nyblade, L et al. 2013. "A brief, standardized tool for measuring HIV-related stigma among health facility staff: results of field testing in China, Dominica, Egypt, Kenya, Puerto Rico and St. Christopher \& Nevis," J Int AIDS Soc 16(3 Suppl 2):18718.

16. Health Policy Project. Measuring Stigma and discrimination among health facility staff: comprehensive questionnaire. Washington, DC: Futures Group, Health Policy Project; 2013. 


\section{LINKUP}

Link Up aims to improve the sexual and reproductive health and rights (SRHR) of one million young people affected by HIV across five countries in Africa and Asia. The project is being implemented by a consortium of partners led by the International HIV/AIDS Alliance.

For more information, visit www.link-up.org

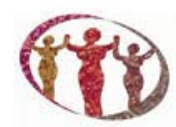

ATHENA
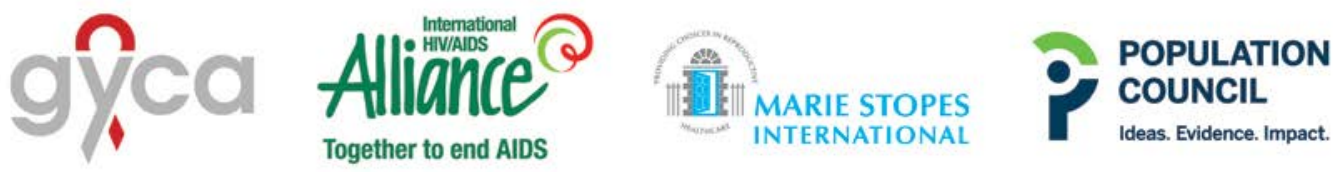

STOP

AIDS

NOW!

\section{$A S^{\circ}$}
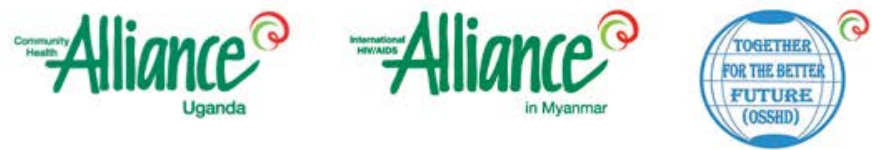

Government of the Netherlands Funded by the Ministry of Foreign Affairs of the government of the Netherlands.

POPULATION COUNCIL

Ideas. Evidence. Impact.
The Population Council confronts critical health and development issues-from stopping the spread of HIV to improving reproductive health and ensuring that young people lead full and productive lives. Through biomedical, social science and public health research in about 50 countries, the Council works with our partners to deliver solutions that lead to more effective policies, programs, and technologies to improve lives worldwide. Established in 1952 and headquartered in New York, the Council is a nongovernmental, nonprofit organization with an international board of trustees.

Suggested citation: Population Council. 2016. "Reducing provider-held stigma and improving client satisfaction in Bangladesh: Results from a Link Up evaluation,” Link Up Study Brief. Washington, DC: Population Council.

\section{www.popcouncil.org}

(c) 2016 The Population Council, Inc. 